\section{O USO DE METÁFORAS COM UM ADOLESCENTE EM PROCESSO PSICOTERAPÊUTICO FAMILIAR}

\author{
THE USE OF METAPHORS WITH AN ADOLESCENT \\ IN A FAMILY PSYCHOTHERAPEUTIC PROCESS
}

\section{EL USO DE METÁFORAS CON UN ADOLESCENTE EN UN PROCESO PSICOTERAPÉUTICO FAMILIAR}

RESUMO: Neste artigo, buscamos ressaltar as contribuições que as metáforas proporcionam para ampliar os recursos conversacionais entre psicólogo e cliente. Para compreender e refletir, portanto, o processo da família, nosso olhar conversou com o construcionismo social, bem como com as práticas colaborativas e narrativas. 0 estudo de caso aqui apresentado se refere a um recorte de um processo psicoterápico familiar. 0 foco, no entanto, serão as sessões das quais 0 adolescente, que estava em período de adoção, participou individualmente. Estas foram escolhidas para exemplificar a forma como coconstruímos a utilização das métáforas, as quais foram utilizadas e propriciaram a conexão da dupla cliente-terapeuta, possibilitando ressignificar os sentimentos e emoções desse adolescente sobre algumas questões importantes da sua história, incluindo a estigmatização que marcava suas falas sobre quem acreditava ser - um adolescente malvado e não amado.

Palavras-chave: Metáforas; Processo psicoterapêutico; Adolescência; Construcionismo social; Práticas colaborativas e dialógicas.

ABSTRACT: In this article, we seek to highlight the contributions that metaphors provide to expand conversational resources between the psychologist and the client. In order to understand and reflect, therefore, the family process, we stablished a dialogue with social constructionism, as well as with collaborative and narrative practices. The case study presented here refers to a cut-off of a family psychotherapeutic process. The focus, however, will be the sessions in which the teenager, who was in the adoption period, participated individually. We chose cyut-offs from these sessions to exemplify the way we co-constructed the use of metaphors, which were used and enable the connection of the pair client-therapist, making it possible to give a new meaning to the feelings and emotions of this adolescent about some important issues in his history, including the stigmatization that marked his lines about who he believed to be - a wicked and unloved teenager.

Keywords: Metaphors; Psychotherapeutic process; Adolescence; Social constructionism; Collaborative and dialogical practices.

RESUMEN: En este artículo, buscamos resaltar las contribuciones que las metáforas proporcionan para expandir los recursos de conversación entre el psicólogo y el cliente. Para comprender y reflejar, por lo tanto, el proceso familiar, nuestra visión hablada con el construccionismo social, así como con práticas colaborativas y narrativas. El estudio de caso presentado aquí se refiere a un resumen de un proceso psicoterapéutico familiar. El enfoque, sin embargo, serán las sesiones en las que el adolescente, que estaba en el período de adopción, participó individualmente. Elegimos recortes de estas sesiones para ejemplicar la forma en que co-construimos el uso de metáforas, que se usaron y permitieron la conexión del doble cliente-terapeuta, lo que permitió volver a significar los sentimientos y emociones de este adolescente sobre algunos temas importantes en su historia, incluida la estigmatización que marcó sus líneas sobre quién creía que era: un adolescente malvado y no amado.

Palabras clave: Metáforas; Proceso psicoterapéutico; Adolescencia; Construcionismo social; Prácticas colaborativas y dialógicas.

\section{MARIANA PERES \\ TRAJANO}

MONICA DUARTE DA SILVA GONÇALVES ${ }^{1}$

${ }^{1}$ Instituto Familiare, Florianópolis/SC, Brasil
Recebido em 26/11/2019 Aprovado em 02/06/2020 


\section{INTRODUÇÃo}

A inspiração para a elaboração deste artigo surgiu a partir das conversações entre supervisora-supervisionanda, nas quais reflexões da prática clínica levaram à busca por respostas para algumas questões teóricas, que estão, e algumas vezes permanecem, como pano de fundo dos fazeres da clínica com crianças e adolescentes.

A inquietação que motivou a escrita deste texto se desenvolveu frente a um atendimento famíliar, o qual foi solicitado por um casal formado por duas mulheres que estava em processo de adoção de duas crianças: uma menina de seis e um menino de dez anos. A demanda familiar recaía sobre a dificuldade, como expressada pelas mães, "em educar" o filho mais velho, ou seja, como dizia a família: ele era um problema. Então, este chegou à terapia com dez anos e encerrou o processo com treze anos, já como um adolescente. Cabe destacar que a família foi atendida pela primeira autora, sendo a segunda autora sua supervisora. Juntas, nas várias conversações sobre o processo de coconstrução das sessões da família, percebemos a riqueza do uso das metáforas como recurso terapêutico. Apresentar esse recurso e refletir sobre ele, bem como discutir outros temas que fizeram parte desse processo, pode contribuir para a promoção e ampliação do debate entre os profissionais da área, dilatando as possibilidades de atuação terapêutica.

Em virtude de o nosso referencial teórico estar baseado no olhar do construcionismo social, contando ainda com influências das práticas colaborativas, é importante explicitar que compreendemos o ser humano em permanente processo de coconstrução por meio das e nas relações sociais e históricas. Gergen e Gergen (2010, p. 19) nos lembram que cada um constrói "o mundo de forma diferente, e esta diferença encontra-se enraizada em nossas relações sociais, a partir das quais o mundo se tornou o que é". Na relação terapêutica, o paciente é o expert da sua história, ou seja, paciente e psicoterapeuta são colaboradores na construção da psicoterapia, pois, embora seus saberes sejam diferentes, estes são iguais em importância. A escuta e a curiosidade são instrumentos fundamentais nesse processo, tanto por parte do cliente como por parte do(a) terapeuta (Rasera, 2018).

Entretanto, não podemos deixar de ressaltar que houve uma mudança de paradigma ao se afirmar que cliente e psicoterapeuta são colaboradores do processo psicoterápico. Este entendimento não é uma tarefa fácil, principalmente para nós, que fizemos parte de uma época histórica e cultural calcada no paradigma positivista, no qual o tecnicismo, a cultura da aptidão e inaptidão, os diagnósticos fechados, que fazia com que as pessoas virassem apenas mais um caso, eram a verdade absoluta. Em outras palavras, fala-se aqui de uma época em que a ciência, mesmo aquela que estudava o humano, era baseada na racionalidade moderna, com seus critérios positivistas, cujo empirismo tinha como paradigma o tripé simplicidade, estabilidade e objetividade. O olhar o qual nos desafiamos a coconstruir na nossa prática clínica pretende dar um salto qualitativo em relação a esse paradigma da modernidade

1 Será utilizada a palavra "posição" em vez de "papel" ou mesmo "função", pois a primeira mostra carrega uma ideia mais dinâmica, referindo-se a algo que não é cristalizado, mas que pode mudar de posição a qualquer momento. Função e papel, por outro lado, são conceitos mais fixos, por isso, a preferência por posição. e busca a noção de que a pessoa precisa ser vista como contextualizada, histórica e em relação. Enquanto na ciência tradicional, de inspiração claramente empírica, a tríade acima citada trazia a possibilidade de se reduzir os fenômenos a verdades, como explicações absolutas, a nova ciência, que veio no bojo da pós-modernidade e na qual embasamos nosso olhar, mostra que o mundo é relacional, marcado pela linguagem e está em constante movimento. Assim, os conceitos-chave desse novo olhar são: a complexidade, a instabilidade e a intersubjetividade (Vasconcellos, 2002).

Então, esse novo modo de enxergar o paciente terapêutico propicia uma descristalização das posições ${ }^{1}$ das pessoas nas relações. A subjetividade não é mais um "ser abstrato" formado apenas pelos aspectos intrapsíquicos, porém, 
passa a ser constituída por vários outros aspectos de sua cultura, do seu contexto e de possibilidades de novas narrativas. Ademais, nesse novo paradigma, em vez de se falar apenas em subjetividade, esta é ampliada em direção à ideia de intersubjetividade, ou seja, da coconstrução, pois o relacional passa a ser primordial para o entendimento do processo da pessoa que está em constante movimento.

Nesse sentido, as práticas terapêuticas pós-modernas oferecem uma postura inovadora frente às pessoas que nos procuram, bem como uma mudança nos paradigmas que embasam nosso fazer profissional. Essas práticas nos permitem estar presentes nas relações de uma forma crítica e reflexiva, trazendo para os encontros questionamentos sobre as verdades absolutas, promovendo a transformação e a inovação de narrativas consolidadas que, muitas vezes, produzem sofrimento e estagnação (Anderson, 2017a).

Nossa prática clínica se identifica com os mesmos pressupostos filosóficos que Anderson (2009) esclarece ao embasar sua prática, a saber:

1. Sistemas humanos são sistemas linguísticos geradores de significado. 2. Sua construção da realidade são formas de ação social, e não processos mentais individuais independentes. 3. A mente individual é uma composição social, e o self, portanto, torna-se uma composição social relacional. 4. A realidade e o significado que atribuímos a nós mesmos, aos outros e às experiências e aos eventos de nossas vidas são fenômenos interativos criados e experenciados por indivíduos em conversações e ação (por meio da linguagem) uns com os outros e consigo mesmo. 5. A linguagem é gerativa, traz ordem e significados às nossas vidas e ao nosso mundo e funciona como uma forma de participação social. 6. O conhecimento é relacional e está incutido e é gerado na linguagem e em nossas práticas do dia a dia. (p. 4)

O processo psicoterapêutico, então, embasado nessa postura filosófica, se torna um espaço no qual os diálogos acontecem de forma colaborativa e, muitas vezes, podem ser transformadores, uma vez que eles permitem compartilhar as revisitações e reinterpretações de significados e entendimentos, gerando novos pensamentos, emoções, sentimentos, expressões e ações (Anderson, 2017b).

De acordo com esse entendimento, segundo o qual o momento da sessão psicoterapêutica é uma articulação das expertises de cada um dos envolvidos, as emoções e inquietações do terapeuta são parte das ferramentas principais para o processo. Ao entender que cada um tem a sua expertise, promove-se a autonomia para que cada um possa ser o ator e autor da sua própria narrativa. Conforme Anderson (2009), é importante que um terapeuta se permita adotar uma postura de incerteza, em que a dúvida seja bem-vinda e utilizada como recurso para ampliar as conversações com seu paciente. Portanto, um recurso importante para o terapeuta é o espaço da supervisão, entendido por nós como um lugar para refletir, coconstruir e utilizar novos recursos, novos diálogos sobre o processo terapêutico.

Trabalhar, portanto, embasado nessa concepção pós-moderna de homem e mundo com crianças e adolescentes é um convite para uma viagem a um mundo de imaginação, de fantasias, onde a realidade precisa de tradução, os problemas precisam de espaço, de palco e de vozes. Nós, adultos e terapeutas, somos convidados a desenvolver nossa flexibilidade e criatividade a fim de conseguirmos nos envolver nesse processo de (re)descoberta do mundo da fantasia e do lúdico. Normalmente, o trabalho com crianças e adolescentes já é uma tarefa complexa, que inclui no setting terapêutico os pais e/ou responsáveis. O psicoterapeuta tem o desafio de 
desenvolver no seu dia a dia a postura de acolher e se vincular às necessidades dos responsáveis pelo desenvolvimento biopsicossocial da criança e, assim, promover um espaço reflexivo e inclusivo para todos os familiares nesse espaço de coconstrução de (possíveis) novas narrativas, fornecendo também novos óculos para olhar para esse desenvolvimento. Em outras palavras, o que se busca, por meio dos recursos conversacionais, são novas maneiras de se relacionar que proporcionem maior satisfação para a família no processo de coconstrução de suas histórias (Grandesso, 2012, 2017; Müller, 2017; White, 2012).

A principal característica da psicoterapia com crianças e adolescentes, mesmo que seja junto com a família, está na possibilidade de se utilizar o lúdico como recurso relacional. Uma das formas de adentrar o lúdico, no entanto, está no uso das metáforas, recurso linguístico que se apresenta por meio de analogias, deslocando e ampliando significados, e que facilita a comunicação de sentimentos que não entendemos ou sobre os quais não conseguimos falar. As metáforas ${ }^{2}$ são, portanto, figuras de linguagem que consistem no uso de uma palavra ou expressão fora de seu sentido literal, procedimento que evidencia um dos seus sentidos implícitos (ou sentido figurado) e estabelece uma relação de analogia entre dois elementos a princípio diferentes. Grosso modo, pode-se dizer que a metáfora é uma espécie de comparação, porém, feita sem o uso dos elementos linguísticos comumente usados nesse processo ("como", "tanto quanto", "igual a" etc.).

Conforme concluem em seu artigo Grandesso e Paschoal (2014), as metáforas ampliam o conhecido e abrem espaço para o não conhecido, mas não podem ser algo que nos deixe cegos para outros pontos importantes no processo do cliente. Precisamos construir seus significados junto com o paciente e utilizá-las para:

Falar de forma mais lúdica, dizer muito com pouco, permitir a autoria da própria história, criar conexões entre os participantes, muitas são as formas de vida favorecidas por metáforas, além de ampliar as possibilidades de compreensão entre clientes e terapeutas. Independentemente de qual metáfora, de qual história utilizar, qual será a mais ou menos viável, o importante é que faça sentido para o cliente e que ele queira caminhar nesta direção. Dessa forma, a metáfora poderá ser um elemento importante na organização da conversa terapêutica sobre as vivências do cliente, no surgimento de uma nova narrativa mais libertadora, e na geração de um contexto que possibilite mudanças a partir de novos significados construídos. (Grandesso \& Paschoal, 2014, p. 41)

Com crianças e adolescentes, esse recurso se coloca como ponte e oferece oportunidades para o terapeuta coconstruir novas histórias e novos significados. Dessa forma, pode-se encetar novas conversações, facilitando a construção da relação e ainda proporcionando o acesso a novas narrativas e, principalmente, sentidos até então ocultos nas situações trazidas pelo cliente (Grandesso, 2012; Müller, 2017).

Nesse contexto, a postura terapêutica, então, pode ser entendida metaforicamente como uma ponte entre duas ilhas, sem, porém, que seja necessário ao terapeuta trazer o cliente para outra ilha, nem ao cliente levar seu terapeuta para sua própria ilha. Na verdade, o que se pretende é que ambos possam trocar, compartilhar e se aproximar, visitando um a ilha do outro. Anderson (2017b, p. 94) afirma que

2 Recuperado de https//www. significados.com.br/metafora/ "o diálogo é uma atividade relacional e colaborativa" o que, num processo terapêutico, é representado pelo entrelaçamento do escutar, ouvir e falar. Assim, esse percurso 
de vai e vem nas ilhas, de reconhecimento e de construção dos novos significados por meio das metáforas, promove o vínculo e o cuidado da relação terapêutica.

Neste artigo, então, buscamos explorar, a partir de um recorte de estudo de caso que envolveu uma família, as possibilidades que o uso de metáforas proporcionou para a ampliação dos recursos conversacionais tanto do processo psicoterapêutico familiar como do adolescente em período de adoção. Apesar do enfoque não estar na adoção, mas nas metáforas, achamos interessante enfocar a questão da adoção, pois esta ocupava posição central no processo do cliente.

\section{A ADOÇÃO E O PROCESSO TERAPÊUTICO}

Falar sobre adoção é entrar em contato com histórias difíceis, muita vezes carregadas de abandonos e violências. $\mathrm{O}$ medo e o cuidado de trazer à tona as narrativas carregadas de sofrimento emocional ressoam no ambiente e no corpo dos que ali estão como testemunhas desses diálogos e contações de histórias. O espaço psicoterapêutico abre lugar para o compartilhar das histórias e visões de mundo dos envolvidos nesse processo, buscando viabilizar um ponto de encontro entre essa família em construção e possibilitar a composição de novas narrativas para ambas as partes. A esse constante movimento e entrelaçamento entre a criança adotada e os pais adotantes dá-se o nome de processo de pertencimento (Schettini, Amazonas, \& Dias, 2006).

O processo de pertencimento faz parte dessa nova família e, de fato, não se inicia ou encerra numa declaração judicial ou na mudança para uma casa nova. Ele leva tempo, exige dedicação, além de envolver encontros e desencontros. Muitas vezes, são dias, meses, anos de construção. É preciso atenção e muito afeto, pois o processo de compartilhar histórias vem carregado de emoção, de dores e de confusão (Faleiros \& Moraes, 2014; Schettini, 2009).

Essas histórias podem produzir verdades cristalizadas a respeito das pessoas e do mundo. As narrativas constroem óculos invisíveis que permitem os ajustes dos olhos, as leituras das imagens e das situações que vivemos. Quando essas histórias dominantes são carregadas de sofrimento, injustiças, abandonos, sensação de incompetência e de fracasso, esses óculos fazem com que percamos o papel de autoria de nossa vida. Tornamo-nos coadjuvantes da história (Grandesso, 2012; White, 2012).

A psicoterapia propicia a oportunidade de questionar a cristalização desses óculos e a vivência com novas lentes, um trabalho artesanal entre terapeuta e cliente em busca de recursos relacionais que auxiliem a vida do sujeito. O contexto psicoterapêtico oferece um lugar seguro e acolhedor para auxiliar no acompanhamento e na construção desse laço entre criança e pais, tendo em vista a psicoterapia como potencializadora da reconstrução de significados.

\section{MÉTODO}

Este artigo é um recorte de um estudo de caso clínico que tem como característica promover a discussão entre o fazer prático-terapêutico e o conhecimento científico. Os participantes deste estudo são Gamora (mãe adotiva), Ororo (mãe adotiva), Banner (filho adotivo) e Estelar (filha adotiva), porém o enfoque/recorte será sobre cinco sessões realizadas individualmente com Banner durante os três anos (que totalizaram sessenta sessões) do processo psicoterápico familiar. O intuito, então, é refletir o uso de metáforas como recurso conversacional no contexto psicoterapêutico com crianças 
e adolescentes. Os dados foram analisados a partir da perspectiva construcionista social, com influências das práticas colaborativas bem como da narrativa (Anderson, 2017a, 2017b; Grandesso, 2012, 2017; Müller, 2017; White, 2012).

A ideia de estruturar esse caso clínico num artigo científico veio após o encerramento do processo terapêutico, incentivado pela supervisora, a qual desde o início insistiu no registro contínuo das sessões, pois percebia como o trabalho que estava sendo realizado poderia contribuir para discussões sobre as metáforas no processo psicoterapêutico. Nesse sentido, as mães (Gamora e Ororo) foram consultadas sobre a possibilidade de realização deste estudo e assinaram o termo de consentimento livre e esclarecido, no qual autorizaram esta produção científica.

Cabe ainda explicar uma questão importante no estilo da linguagem do presente artigo. Utilizamos a primeira pessoa do plural, pois escrevemos juntas e acompanhadas das vozes que compõem nosso fazer clínico. No entanto, quando formos descrever como foram realizadas as sessões e as conversas internas da terapeuta nesses momentos, usaremos a primeira pessoa do singular a fim de não perdermos a autenticidade dos atendimentos, porém nas discussões e análises retomaremos o plural.

\section{DESCRIÇÃO DOS PARTICIPANTES: OS NOMES FICTÍCIOS DOS PARTICIPANTES}

Esse processo terapêutico teve, além dos parceiros conversacionais, cliente, psicoterapeuta e supervisora, alguns outros parceiros não tão comuns, ou seja, eles eram super-heróis, que, entrelaçados por metáforas, foram recursos terapêuticos presentes do início ao fim desse processo. As metáforas, conforme Grandesso e Paschoal (2014) promovem a construção de significados e a reorganização de histórias do paciente em narrativas mais leves, libertadoras e conectadas emocionalmente, propiciando ainda a emergência de outros sentidos subjacentes ao discurso da pessoa.

A escolha dos nomes fictícios para identificar os participantes deste estudo está alinhada com a metáfora utilizada pelo paciente identificado, Banner, que era o Incrível Hulk, sendo que esta circulou durante os atendimentos que serão discutidos a seguir. Assim, ao paciente, escolhemos dar o nome do personagem principal da série, David Banner, o cientista que, após um acidente em seu laboratório, recebeu uma forte descarga de energia gama e, a partir disso, ao ficar furioso ou com medo, se transformava em um humano monstruoso e de força descomunal que entrava em conflito contra aquele que lhe infligia injustiças.

Os outros nomes, escolhidos para preservar as pessoas desse processo, não foram retirados das conversações com Banner. Entretanto, optamos em continuar na mesma linha dos super-heróis, escolhendo personagens que compunham a mesma "rede social" do Incrível Hulk e que, para nós, continham alguns aspectos encontrados nas narrativas dos participantes sobre si mesmos. A seguir, apresentamos um pouco das características desses personagens.

A Estelar, irmã de Banner, é uma personagem marcada pela escravidão, por experimentos doentios, mas que ainda assim tem uma atitude positiva em relação à vida, sempre buscando se reinventar, sendo este o seu poder. Gamora, umas das mães, é conhecida como uma das mulheres mais poderosas, pois é aúnica sobrevivente de sua espécie, sendo adotada por Thanos. Por último, Ororo, a outra mãe, é a Tempestade da série X-Men, capaz de dominar os fenômenos naturais, portanto, controla os ventos, a chuva, a pressão atmosférica, os movimentos marítimos, entre outros fatores da natureza. É uma das personagens mais poderosas da Marvel.

Nova Perspectiva Sistêmica, v. 29, n. 67, p. 23-40, agosto 2020. 


\section{Primeira sessão: conhecendo a história de Banner}

Um menino de dez anos de idade, Banner, foi encaminhado pela escola ${ }^{3}$ a qual frequentava para a terapia individual comigo. Em virtude disso, o primeiro contato foi realizado apenas com as mães adotivas, pois elas haviam enfatizado nas mensagens trocadas por whats app e contato telefônico a necessidade de a terapia ser apenas para o filho, mostrando, por meio das falas, uma necessidade de contar a história de Banner e também o sentimento de impotência frente a como lidar com o menino. Banner ficou sentado na sala de espera por toda sessão. Encontrei com ele apenas na segunda sessão, junto com as mães.

Durante os primeiros minutos dessa sessão exclusiva com as mães, os relatos eram conturbados, inundados de medo, de raiva, de desespero, de aperto no peito e muito sofrimento. Eu sentia tudo junto com elas e percebia-me com um questionamento interno com meus parceiros conversacionais White, Grandesso, Anderson, Müller, minha supervisora, professores de graduação e colegas de profissão: o que poderia ser tão pavoroso na história de um menino de apenas dez anos? Esse questionamento me guiou por todo o processo. Para finalizar a sessão, expliquei às mães a diferença entre uma terapia individual e uma familiar e acordamos seguir então o segundo estilo.

O casal relatou que, aos seis anos de idade, Banner fora institucionalizado junto à irmã Estelar, que à época estava com três anos de idade. Abusos físicos, psicológicos e sexuais acompanharam o percurso das crianças, que haviam sido institucionalizadas por maus-tratos e sofrido abusos físicos e sexuais dentro da instituição de acolhimento e, por fim, abusos psicológicos durante adoções, incluindo até devolução.

Logo após a institucionalização, Banner foi diagnosticado com transtorno afetivo bipolar. Começaram as idas a psicólogos e psiquiatras, as noites mal dormidas e os pesadelos com monstros, bruxas, velhos e velhas que aterrorizavam Banner. Assim, iniciaram os tratamentos com antipsicóticos e estabilizadores de humor, bem como as repetências na escola. Como consequência, o menino afirmava que "era impossível prestar atenção, eu tava dormindo sempre" (Banner).

Aos nove anos de idade, Banner foi adotado por Gamora e Ororo, junto à sua irmã. Gamora é pedagoga e professora acadêmica. Soube do histórico escolar de Banner e decidiu que seria o seu projeto ajudar esse menino repetente, institucionalizado e com "problemas mentais". Ororo nunca pensou em ser mãe, não tinha esse desejo, mas por amor à Gamora decidiu embarcar nesse projeto de vida. As mães, por conta do trabalho de Ororo, moravam em cidades diferentes. As crianças ficavam com Gamora e, aos finais de semana, Ororo voltava para casa.

Após mais ou menos um ano de adoção dos irmãos, os abusos sexuais, dos quais Banner era o autor, voltaram a acontecer dentro da casa de Gamora e Ororo. Ao questionarem Banner sobre o que havia acontecido, o menino dizia que era normal e que o havia aprendido na instituição onde ambos foram acolhidos. As mães, apavoradas, foram até a instituição e a resposta que obtiveram foi a seguinte: "isto é normal nesses lugares" (Gamora e Ororo). A partir daí, as mães decidiram separar a família, como estratégia de proteção às crianças: Estelar morava com Gamora e Banner morava com Ororo.

3 A escola apenas encaminhou Banner, não requisitando nenhuma conversa com a psicoterapeuta. Esta, por entender a necessidade dessa conversa, acabou procurando a instituição e obteve algumas informações sobre o comportamento "inadequado" em sala de aula. Logo após, ele mudou de colégio e não houve mais comunicação entre as partes. 
Na sessão seguinte, Banner chegou com as mães. As queixas das mães, além de todo o histórico de abuso de Banner, eram em relação à intolerância, à frustração, à raiva e à agressividade, passando para a violência física e verbal quando elas se opunham à sua vontade, quando algo saía do seu controle ou quando ele era corrigido. Na escola, apareciam queixas sobre a relação interpessoal de Banner com os colegas e com os professores.

Novamente, aquele questionamento interno emergiu: um menino de apenas dez anos de idade, o que tem de tão pavoroso? Banner entrou no consultório e me deparei com um menino o qual conversava comigo de uma forma que chamou atenção. Percebi uma falta de vocabulário para explicar o que sentia, bem como dificuldades para descrever situações do seu cotidiano. Eu me apresentei a Banner e iniciamos a sessão com o baralho das emoções (Caminha \& Caminha, 2008), como recurso de formação de vínculo inicial e estratégia de introduzir o processo de reconhecimento emocional na família, uma vez que Gamora e Ororo estavam presentes na sessão. Todos jogamos.

Uma das minhas primeiras perguntas no início de processos terapêuticos, principalmente com crianças e adolescentes, é se todos sabem o motivo de a família estar naquela sessão de terapia. A mãe Gamora falou para Banner que ir à terapia era devido aos abusos com Estelar e da separação da família por conta dos comportamentos “inaceitáveis" de Banner.

Quando Banner escutou toda a fala da mãe, saiu correndo do círculo onde estávamos jogando o jogo das emoções e se escondeu atrás das poltronas. Ficou me espiando pelo cantinho. As mães paralisaram e também me olhavam fixamente. Aqueles olhos me observando, tentando perceber qual a minha reação frente às falas das mães, me deram a sensação de que Banner estava aguardando o momento em que eu estaria aliada às mães, compartilhando do mesmo pensamento, repreendendo-o e dizendo o quanto ele era um menino malvado.

Entendemos, eu e a supervisora, então, que a trama de significados relacionais (Grandesso, 2017) de Banner era esta: o menino malvado e não amado. Essa narrativa, ao mesmo tempo que incômoda e desconfortável, era a conhecida por Banner.

$\mathrm{Na}$ sessão percebi, nas falas das mães naquele dia, que em virtude dos abusos sexuais, que Banner tanto sofreu como cometeu. Utilizaram, por várias vezes, as palavras "malvado" e "não amado", quando contavam como ele era chamado pelas pessoas que trabalhavam nos abrigos em que morou, bem como várias vezes na sessão, quando, ao se exaltarem, repetiam as mesmas palavras diretamente a ele. Então, era assim que as pessoas o reconheciam e assim que ele se narrava e ocupava uma posição conhecida e aparentemente "segura" de pertencimento.

Todavia, os significados e as histórias que conhecemos e (re)contamos de nós mesmos são construídos nas relações e experiências vividas, nunca são de autoria solitária, são coconstruídos num constante processo de viver e reinventar nossas vivências. Grandesso (2017) aponta que, por meio das conversações, é possível abrir um espaço para falar de temas densos de uma forma leve e fluida e isso nos encorajava a continuar trabalhando com Banner, mesmo quando a terapeuta via aqueles olhinhos assustados atrás das poltronas aguardando pela mesma narrativa, conhecida e (des)confortável, e chegava nas supervisões com a sensação de que não conseguiria aguentar tanto sofrimento. Era nesse momento que abríamos espaço para as vozes internas dialogarem conosco.

No momento em que Banner foi para trás do sofá, intervi dizendo para as mães e para Banner que temos partes das nossas histórias que demoramos para 
revelar às pessoas e que, para isso acontecer, precisamos desenvolver a sensação de segurança, de pertencimento e de aceitação. Banner me olhou surpreso, curioso, e aos pouquinhos foi saindo de trás do sofá. As mães, consequentemente, falaram estar surpresas com a narrativa da terapeuta, pois, para elas, isso demonstrou um respeito por Banner que nem mesmo elas tinham entendido ser necessário, afinal, parecia que, por ele ter passado por tantas coisas, ele já estava acostumado com isso e indiferente a essas palavras. Senti que abrimos um espaço para começar a refletir sobre as narrativas dominantes trazidas pela família, escola e o próprio Banner.

\section{Terceira sessão: encontrando com Banner individualmente}

Dentro do acordo feito com as mães sobre a modalidade de terapia familiar, foi combinado que, em alguns momentos, seria interessante, para esclarecer alguns pontos da história pessoal, algumas sessões individuais com os membros da família

Neste encontro, éramos somente eu (terapeuta) e Banner. Logo no início da sessão, propus utilizarmos o baralho das emoções (Caminha \& Caminha, 2008) como recurso de aquecimento para a sessão. Percebi - por algumas falas e comportamentos de Banner - a sua desconfiança em compartilhar comigo sua história, suas emoções e seus sofrimentos. O baralho das emoções, no entanto, foi se transformando, na interação com Banner, em um jogo de memória que fomos construindo juntos. Banner então sugeriu que, quando pegássemos as cartas iguais, com as mesmas emoções, tínhamos que reproduzir a expressão dessa emoção.

Depois de uns 15 minutos de sessão, Banner disse que não queria mais brincar de memória, falando que fazer as caras o deixara triste e com dores no corpo. Ele estava agitado, andando de um lado para o outro, jogando almofadas para todos os lados, e então perguntei: "jogar as almofadas te alivia?", ao que ele respondeu: "não sei, só que parece que tem algo aqui" - apontou para o peito -"que precisa sair". Pensei que talvez um jogo que expressasse o que tinha no peito seria interessante e criei uma possibilidade diferente: a brincadeira das perguntas. As regras eram simples: cada um faria uma pergunta para o outro jogando a almofada. No meu entendimento, naquele momento, o jogo da memória se transformou em um jogo de expressão das emoções e Banner, de alguma forma, foi se conectando com aquelas cartinhas e os "temas difíceis" estavam borbulhando dentro dele.

Em nossas conversações, eu e a supervisora consideramos que o trabalho com crianças e adolescentes requer estar atento a cada detalhe das brincadeiras. O lúdico é a linguagem dos "temas difíceis" e torna-se o processo simbólico das contações de histórias (Grandesso, 2012; White, 2012). Contudo, requer também uma possibilidade de flexibilidade para acompanhar o cliente para o caminho que ele deseja, sem impor os trajetos que consideramos adequados.

Banner começou a fazer as perguntas: "por que você tá querendo me ouvir? É porque a gente te dá dinheiro, né?” (Banner). Respondi que não, que estava ali porque gostaria de ajudá-lo, que o objetivo daquele espaço era para ele contar a história dele e para que, juntos, víssemos todas as partes dessa história de um jeito diferente. Nesse momento, Banner deu um sorriso gigantesco, como se estivesse se encantando com aquele espaço e com a minha resposta.

De qualquer forma, como conversado com a supervisora, esse também é o nosso trabalho. E como explicar para uma criança/adolescente que nosso trabalho é ajudálo a entender o seu emocional, a sua história, por meio do vínculo e, ao mesmo tempo, cobrar por isso? Na relação com a supervisora, fomos compreendedo que vozes internas eram estas que acreditavam, de alguma forma, que cobrar pela terapia era algo estranho. A relação entre a psicoterapia e a cobrança é complexa 
e importante de ser discutida, pois talvez seja uma ressonância presente em muitos terapeutas. Porém, dada a complexidade desse tema, certamente mereceria destaque em outro artigo.

Voltando ao jogo, era minha vez de jogar a almofada e fazer uma pergunta. Perguntei se ele sabia o que as mães tinham conversado comigo na primeira sessão. Fiz essa pergunta porque, no primeiro encontro, Banner estava na sala de espera e me viu entrando e saindo com as mães do consultório. Fomos apresentados pelas mães e fiquei pensando: o que será que ele imaginou que estávamos fazendo lá dentro? Ele me respondeu que não fazia nem ideia. Chegou a vez do Banner e ele me perguntou de volta: “o que elas te falaram?". Respondi que as mães conversaram comigo sobre o que havia acontecido no abrigo e com a Estelar. Contei para Banner que eu sabia das partes da história dele que envolviam episódios de abusos. Respondi a verdade. Não queria inventar um capítulo que não fazia parte da história. Fiquei pensando quantas mentiras já haviam sido contadas a Banner, quantos "faz de conta" haviam feito parte dos seus 10 anos de idade. Não poderia ser mais uma pessoa a fazer isso. A relação terapêutica precisa ser construída com respeito e sinceridade.

Banner olhou para mim como se eu o tivesse traído: "eu não quero mais ser seu amigo, me arrependi de ter conversado com você, não posso confiar em você". Banner saiu correndo da minha frente e foi se esconder atrás do sofá, aquele lugar que já era conhecido das sessões anteriores.

Nesse momento, eu não sabia o que fazer. Meu primeiro pensamento foi que eu não deveria ter falado nada, pois perdera o paciente. Michel White me veio à mente e disse: incomum demais! Tentei conversar, falar que eu não estava ali para julgálo, que ele poderia confiar em mim. Nada disso funcionou. Ele continuava atrás do sofá, da cortina, de tudo. Meus diálogos internos estavam a todo vapor: o que fazer? Provoquei-o demais? Será que ele não estava preparado para falar disso? Fui invasiva? Meu principal personagem interno - a autoexigência - tomou conta de mim.

O caso dessa família e, principalmente Banner, em diversos momentos, me fazia sentir tudo isso. Deparava-me com minhas inseguranças enquanto terapeuta e me sentia ameaçada muitas vezes. Era algo estranho, diferente, fazendo com que eu levasse esse caso para supervisão com frequência.

Entendemos em supervisão, por meio de Maesima, Barreto e Beiras (2019), que essas sensações nas relações psicoterapêuticas são ressonâncias e são de suma importância para a formação do vínculo, uma vez que o terapeuta, ao se exercitar nesse lugar de atenção às ressonâncias, se depara com a intensidade das reflexões sobre si, sobre suas vivências e suas relações íntimas. Nesse percurso de consciência das minhas ressonâncias, pude perceber que as minhas inquietações proporcionaram a potencialização do desenvolvimento do meu self, ou seja, do meu jeito de fazer terapia e a forma de ocupar o lugar de terapeuta, me permitindo prestar atenção no que sentia durante as sessões com Banner.

Com essa enxurrada de pensamentos catastróficos e, ao mesmo tempo, egocêntricos, lembrei que Banner gostava muito de pintar/desenhar. Tinha acabado de comprar o livro Jardim Secreto (Basford, 2014) e pensei em utilizá-lo como recurso para me reaproximar dele, sendo este apenas um recurso de aproximação que não foi coconstruído e nem utilizado como uma metáfora. "Banner, eu entendo que você esteja chateado comigo. Sinto muito por isso. Mas enquanto você está aí atrás do sofá eu vou pintar aqui um livro que eu acabei de comprar. Gostaria muito que você viesse junto. Estou te esperando aqui, ok?” (terapeuta). Cerca de dois minutos depois, Banner foi até mim e disse: "você não pinta muito bem, sabia? Vou te mostrar como que se pinta".

Esse momento, compreendido como um pedido de desculpa, por mim e pela supervisora, fez com que Banner se (re)aproximasse e possibilitasse que o vínculo fosse 
reparado na relação, por meio desse acolhimento. Com essa atitude, apresentamos a ele um novo recurso relacional que nos ajudou a lidar com as emoções presentes naquele momento. Alguém poderia sim pedir desculpas por algo que fizera para ele. Esse é um dos momentos do processo terapêutico que consideramos mais importantes para o processo de ressignificação das emoções (Grandesso, 2017), em que a raiva não precisa ficar para sempre, em que os sentimentos e emoções podem ser entendidos como algo transitório com os quais podemos aprender e a partir dos quais é possível nos reaproximarmos uns dos outros. Essa postura corrobora o que Anderson (2009) aponta, isto é, que a postura do não saber do terapeuta traz em si a humildade, pois "trabalhar a partir de uma posição de saber independentemente predetermina as possibilidades e destrói o codesenvolvimento do novo significado por meio de histórias e narrativas geradas na terapia” (p. 115).

Depois de um tempo, perguntei a Banner se ele gostaria de iniciar uma pintura na terapia. Ele logo disse que sim, mas que ainda não confiava muito em mim e precisava de um tempo. Ou seja, é no tempo da relação, não no tempo do cliente ou do terapeuta. Então, eu disse que estava tudo bem e que teríamos esse tempo para nos conhecermos.

O diálogo com o cliente nem sempre é harmonioso. Podem acontecer momentos difíceis, duros, nos quais nos deparamos com dificuldades no momento de troca e de compartilhar significados. Existem momentos em que dissonâncias vão acontecer e cabe a nós, terapeutas/supervisores, pararmos para refletir se estamos contribuindo para que essa dissonância ocorra. Contudo, é a partir do diálogo, interno do terapeuta e externo com paciente, que encontramos, juntos, maneiras diferentes de seguir em frente, de seguir adiante com nossas emoções, vivências e histórias (Anderson, 2017b).

Banner e eu escolhemos um desenho juntos no qual havia uma chave entre as folhas. Enquanto estávamos pintando o desenho, perguntei para ele o que essa chave poderia abrir. Banner olhou para mim e disse: "essa chave abre um portal, tem muita coisa atrás desse portal", me convidando para uma conversa metafórica. Nosso tempo estava terminando e, ao encerrar a sessão, disse para Banner que poderíamos, juntos, descobrir o que havia atrás desse portal, como fazer para entrar, quem poderia entrar, os riscos de entrar etc. Banner olhou para mim e deu aquele mesmo sorriso do início da sessão: “tá, vamos fazer isso na próxima terapia, tá?".

A metáfora aqui demonstrava que existia um mundo à parte, um mundo que escondia muitas coisas e em que era difícil entrar. Assim, o uso de metáforas com crianças e adolescentes viabiliza o diálogo e lança mão do mundo das fantasias e do lúdico para construir com o cliente novas histórias e novos significados (Grandesso, 2012; White, 2012). Nesse caso, supervisora e eu sabíamos que estávamos acessando um lugar novo, escondido e, aparentemente, perigoso. Ainda estávamos falando de emoções, de acolhimento, de relação terapêutica, tudo por meio da metáfora.

\section{Quarta sessão: portal das emoções}

Iniciamos a sessão com a continuação da pintura do nosso desenho. Durante a pintura, perguntei a Banner como fora a semana e ele me contou que estava muito triste e decepcionado. Muitos colegas do colégio tinham perguntado para ele por que ele tinha duas mães. Banner não queria contar que era adotado aos colegas e disse a eles que nascera da barriga da mãe Ororo. Quando pensei em entrar com o baralho das emoções e planejei trabalhar a tristeza, ele me disse: "tá, mas agora não vamos falar disso, vamos ver o portal. Vou desenhar pra ti o portal” (Banner).

Nova Perspectiva Sistêmica, v. 29, n. 67, p. 23-40, agosto 2020. 
Nesse momento, Banner me lembrou que estávamos na ponte entre nossas ilhas e que falar das emoções por meio da metáfora do portal permitia acessar o que estava escondido atrás deste. Com essa mudança de rumo que o paciente trouxe, refletimos, na supervisão, sobre como a terapia colaborativa permite dar voz aos pacientes, aquilo que para ele é seu assunto naquele momento. Nessas práticas, o cliente tem respeitados o seu jeito, o seu ritmo e, principalmente, o que ele quer conversar. Afastar-se do conteúdo passível de uma interpretação determinista é dar espaço para a relação e a possibilidade de nos dedicarmos ao saber que surge a partir do processo em si (Anderson, 2009, 2017a).

Ele então começou a me contar a história por trás do portal: "esse portal leva as pessoas para o passado, mas homens comuns não passam, eles morrem quando tentam entrar. Muitos homens já tentaram, todos morreram”. Perguntei a Banner se alguém, alguma vez, já havia conseguido passar pelo portal. Ele olhou para mim, muito sério, e disse: "Já, o Hulk! Ele foi o único, ele é super-herói”. Fiquei curiosa no momento e perguntei: todos temos um Hulk dentro da gente? Ele acenou com a cabeça que sim. "Vocêtem um Hulk?", perguntei, e ele acenou que sim novamente. Eu então disse para ele: "é, acho mesmo que todos temos um Hulk dentro de nós e que precisamos aprender a conversar com ele de vez em quando. Topas algum dia a gente conversar com o seu?". Ele sorriu.

Nesse ponto, podemos ver a função da metáfora claramente, pois essa figura de linguagem se coloca como recurso de analogia entre dois elementos, ligando aqueles que guardam uma relação entre si, ou seja, essas pessoas que tentaram entrar no portal podem remeter à relação de Banner com a conexão emocional.

Prestando muita atenção no que eu estava falando, Banner fixou o olhar em mim. Continuei: "Banner, e se fizermos uma história do portal e do Hulk? Vamos escrever essa história?”. Banner topou na hora. Dei lápis de cor e papel para Banner e ele fez a capa da história do Hulk e do portal. Encerramos a sessão finalizando a capa da história.

Podemos supor que, naquele neste momento, que Banner estava nos contando como era falar de emoções para ele. Entrar em contato com a tristeza, a raiva e o medo era muito pesado e difícil e, por isso, ele não poderia ir sozinho. Inclusive, ir sozinho era um risco, risco de morte, de perda, de luto, de desconexão. Era perigoso demais isso, ele não podia correr o risco de, novamente, perder tudo e todos ao seu redor. Encerramos a sessão finalizando a capa da história e com a seguinte conversa transcrita literalmente abaixo, na qual busquei mostrar que poderia acolher os sentimentos que ele quisesse me contar:

\section{T: Você acha mesmo que todos nós temos um Hulk dentro da gente?}

B: Acena que sim.

T: Que interessante, porque eu queria te contar que estou acostumada a conversar com outros super-heróis de outras pessoas aqui no consultório que existem dentro delas.

\section{B: Ah, é! Elas são legais? Não são bravas?}

$\mathrm{T}$ : Sim, são pessoas bem legais que às vezes ficavam bravas, triste, com medo. Eu também sinto tudo isto. Sabe que todos nós temos muitos personagens dentro da gente, mas que são pedaços nossos, não a gente inteiro? E se um dia tu quiser, podemos conversar com o teu Hulk.

Nova Perspectiva Sistêmica, v. 29, n. 67, p. 23-40, agosto 2020. 
Na semana que antecedeu a essa sessão, a mãe Ororo entrou em contato comigo e relatou terem ocorrido muitas confusões na escola e em casa. Logo no início da sessão, Banner sentou no sofá e disse que houve coisas boas na semana, mas que xingara uma menina no colégio. Quando perguntei mais sobre o que acontecera para ele xingar a menina, Banner me contou as histórias fora de ordem. Começou pelo fim, voltou ao começo e depois contou o meio da história, tudo de forma confusa. Disse para ele que não consegui entender o que acontecera: "a mãe Ororo só briga comigo, tudo é motivo pra brigar". A raiva e a tristeza tomaram conta da sessão. Banner trancou o choro, começou a se bater e a dizer que iria ser abandonado de novo e que não iriam gostar dele. Apesar de ser uma cena forte, considerei uma mudança de Banner: ele conseguiu expressar, sem se preocupar tanto comigo, as suas emoções confusas. Percebi, com essas falas, que os momentos em que as emoções apareciam eram carregados desses comportamentos agressivos com os outros e com ele mesmo. Todos eles surgiam com a sensação do abandono e de rejeição. Parecia ser sofrido demais estar próximo às emoções.

Quando o vi se batendo demais, gritando que seria abandonado e que ninguém, nunca, estaria ao lado dele, me aproximei de Banner e peguei na sua mão, ao que ele me disse: "eu já sou grande, pode ir pro teu lugar", soltando a minha mão e me olhando de canto de olho. Senti que Banner se assustou quando me viu ali. No meu diálogo interno com a supervisora, lembrei que certamente eu deveria ter pedido permissão antes de me aproximar.

Perguntei se eu poderia ficar ali, ao lado dele, e ele me disse que sim com a cabeça: "Banner, pessoas grandes também choram, também pedem ajuda, também brigam, também sentem raiva, também precisam de momento e espaços de confiança. Afinal, emoções vêm e vão e sinalizam quem nós somos". Banner olhou para mim e disse que queria brincar de Uno ${ }^{4}$. Lembrei de minha supervisora dizendo: sempre respeite a linguagem e o momento do seu paciente, coconstrua os momentos. Baseada em Anderson (2009) e nas práticas colaborativas, entendi que era necessário abandonar a conversa que eu queria ter e aceitar o que era importante para ele. Brincamos então de Uno até o final da sessão. Banner mostrou com seu corpo que se sentiu acolhido, sentiu a emoção e não foi abandonado por ter falado dela e demonstrado-a na minha presença. Aceitei mudar de linguagem, sair das construções linguísticas elaboradas (metáfora) e ir para a concretude (Uno), colaborando com as necessidades do paciente.

\section{Sexta sessão: Hulk e as frustrações}

Banner entrou na sessão pedindo para me mostrar um jogo eletrônico, dizendo que era muito legal e que teria que me mostrar para que nós jogássemos juntos. Banner disse que todos da escola estavam jogando e que ele também era muito bom nesse jogo. Deixei Banner mostrar o jogo e disse para ele que poderíamos jogar uma vez. Banner queria negociar, me pediu três vezes. Disse a ele que poderíamos jogar duas vezes. Ele olhou para mim e disse: "ah, por quê? Mas que saco, eu quero três". Disse a Banner que nós dois poderíamos ceder, flexibilizar. Banner aceitou, porém, não gostou muito.

Quando acabamos de jogar as duas partidas, voltamos para a história do Hulk e do portal. Banner estava desenhando e eu perguntei qual parte da história ele estava contando agora: "o Hulk tem que matar todas as pessoas da terra pra poder sentir outras emoções, porque agora ele tem só a raiva”. Banner me contou que o Hulk tinha que matar todo mundo e depois ir até o portal e voltar no tempo, para que assim

4 Uno é um jogo muito parecido com uma partida de baralho em que ganha aquele que terminar suas cartas primeiro. 
fosse possível viver com todas as emoções, dando espaço para que se relacionasse de maneira diferente e que não fosse só por meio da raiva. Finalizamos a sessão com Banner desenhando a morte do mundo e o retorno do Hulk ao passado pelo portal.

Banner estava nos contando que ele sentia somente raiva e se relacionava somente com a presença dela. O passado fazia parte disso tudo, dessa construção e da linguagem de Banner. Tínhamos sim que voltar ao passado, não da forma adulta, revisitando as situações específicas, falando dos abandonos e dos abusos de fato, mas voltar de uma forma diferente: com o Hulk, com a força do superherói e com um ser humano, a terapeuta, junto dele. Banner precisava se sentir seguro para voltar lá e proporcionar algo diferente do que era conhecido, diferente da destruição. Essa metáfora serviu como uma ponte entre nossos mundos, que nos ajudou por meses a encarar as injustiças que ele sofrera durante sua curta e intensa existência. Diferente do personagem da série, que foge da cidade para não encarar seus sentimentos, nosso Banner foi encarando, a cada sessão, seus sentimentos para compreender e transformar corajosamente sua história. Esse processo levou muitas sessões dedicadas à exploração da metáfora do super-herói angustiado, tanto nas sessões familiares bem como nas individuais de Banner.

Cabe ressaltar que, nas sessões familiares, também conversamos sobre como cada um lidava com a sua raiva, se nas três famílias (a de Banner e Estelar, e nas de Ororo e Gamora) tinham situações que os deixavam tristes. A cada sessão, as histórias aparentemente tão diferentes de cada família se encontravam e se articulavam. Dessa forma, os participantes estabeleceram uma relação de "parceiros no diálogo" (Anderson, 2009), coconstruindo novos significados e novas narrativas. Foram se tornando corresponsáveis pelo bem-estar das relações familiares.

Neste ponto do artigo, daremos um salto nos números de sessões com o intuito ressaltar o objetivo do artigo - o uso das metáforas.

\section{Vigésima quinta sessão: Hulk e Banner, Banner e Hulk}

Iniciamos a sessão falando sobre a consulta com a psiquiatra. Banner disse que foi tudo bem e contou sobre a semana na escola. Ele escolheu o baralho das emoções para brincar durante a sessão. De novo como recurso de aquecimento para a sessão, o baralho foi utilizado como jogo de memória e de mímica. Enquanto jogávamos, Banner pegou as emoções da raiva. Olhei para ele e disse que era a emoção da história que escrevemos. Banner olhou para mim e disse: "ah, que saco, essa coisa de Hulk já deu, que chato!". Essa frase, para nós, terapeuta e supervisora, foi muito impactante, pois mostrava o quanto Banner estava falando com mais facilidade de si. Compreendemos ainda que o Hulk, enfim, foi externalizado e, consequentemente, se tornou conhecido e possível de se tornar um recurso relacional, afinal, o Hulk tem uma força que na vida as vezes é necessária, e não é apenas um impedimento para as relações de Banner com ele e com os outros.

Estávamos, os três, Banner, terapeuta e supervisora, háalguns meses desenvolvendo as histórias do Hulk e as aventuras pelo portal. Muitas idas e vindas nos mundos do passado, do futuro e do presente proporcionaram ao Hulk a possibilidade de sentir diversas emoções nessa trajetória. Tristezas, raivas, medos, alegrias, ansiedades, frustrações, nojos. Finalizamos a sessão conversando sobre esse movimento, que o Hulk tinha voltado no tempo pelo portal e conquistado o objetivo de sentir outras emoções. Banner terminou a sessão com a seguinte frase: "é, acho não sou o Hulk, mas posso pedir para ele aparecer às vezes. Ele não precisa ficar mais bravo por tudo, pode chorar também e ter amigos". Olhei e disse: "que interessante isso! Será que o Hulk pode ser mais tempo David Bruce Banner?”. Ele riu e foi para casa.

Nova Perspectiva Sistêmica, v. 29, n. 67, p. 23-40, agosto 2020. 
Esse trecho é de suma importância, pois mostra como Banner conseguiu dar um outro lugar para o Hulk na sua vida, ressignificando as suas emoções.

\section{Sexagésima sessão: reconstrução de significado e despedida da terapia}

Banner e a família estavam se mudando para outra cidade. Já sabíamos que era o último encontro. Foi a sessão de despedida. No início da sessão, família e eu falamos sobre todo o processo desses três anos de psicoterapia, desde quando as mães aceitaram o processo de psicoterapia de família, até as sessões individuais, principalmente quando ele me viu pela primeira vez até esse nosso encontro de despedida.

A família teve uma ideia e eu aceitei: que tal desenharmos o Banner da primeira sessão e o da última? Ele logo se movimentou, sentou na cadeira e pediu papel e lápis e desenvolveu os dois desenhos. Enquanto ele estava nesse processo criativo, fomos, a família e eu, conversando sobre cada momento, cada lembrança que tivemos, as brincadeiras que inventamos ali, passeios que fizemos, as sessões em família e até mesmo conversamos sobre os momentos difíceis que aconteceram antes de nos conhecermos. Banner foi desenhando, pintando, construindo aqueles retratos.

Nessa conversa, Banner foi falando que, na primeira sessão: "eu sentia que só enxergavam em mim o meu Hulk. Eu só tinha um carão" (refere-se a uma cara grande e assustadora no desenho). Falei a ele: "concordo!". Olhando para o desenho, lembrei de como me assustei com o jeito que contaram quem ele era. Que fiquei me perguntando o que aquele menino tinha de tão horrível. "Sabe, olhando para este desenho, entendo o que senti - senti que faltava uma parte sua e, depois que conheci o Banner, tudo mudou para mim. E para ti?" Ele olhou e disse: "foi legal, né?". Respondi que havia sido um prazer conhecê-lo.

\section{Figura 1 - Banner da primeira sessão}



O Banner da última sessão era um menino com pés, calçados, mãos, cabelos, rosto. Um menino em pé, firme no chão, fazendo um desenho em perspectiva: “imagina que a gente tá vendo de cima, tá?! Isso aqui no meio é o mundo nas minhas mãos. Agora eu posso fazer o que eu quiser” (Banner). 


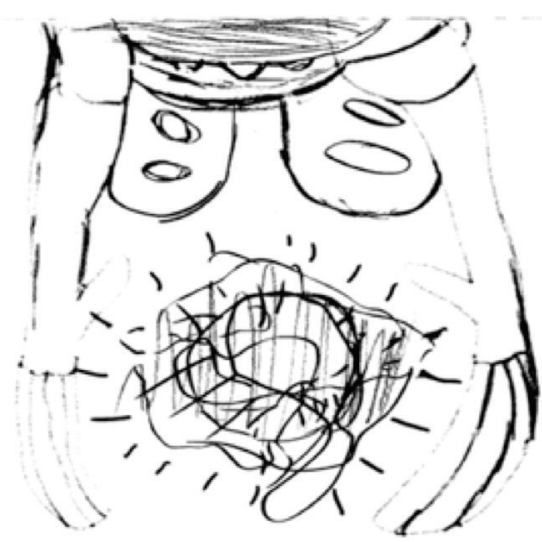

Conversamos sobre os desenhos e sobre o movimento da família em todo esse processo. Falamos de como eles chegaram à terapia e como estavam saindo, principalmente Banner. Quais sonhos ele tinha, quais planos, desejos, ideias para esse novo momento de mudança de cidade e de conhecer pessoas novas. Nosso tempo estava se esgotando e as mães falaram de como foi interessante ver que existe um processo para se sentirem mães. Foi então que Banner me disse: "Queria agradecer por ter acreditado em mim. Obrigado por me dar uma chance".

A dupla, terapeuta e supervisora, se emocionou com essa última frase de Banner e entendeu que ambas também saíram modificadas e que, para olhar para o Hulk de Banner, tiveram que conversar muito sobre seus Hulks pessoais. Trabalhar na perspectiva da coconstrução é desafiador!

\section{CONSIDERAÇÕES FINAIS}

Nesta parte final do artigo, mas não menos importante, gostaríamos de comentar que este recorte de estudo de caso buscou apresentar aos leitores como as metáforas proporcionaram a ampliação dos recursos conversacionais desse processo psicoterápico de um adolescente com histórias estigmatizantes. Durante três anos, nós, supervisora, cliente e terapeuta, construímos e compartilhamos um espaço que permitiu ao menino assustado, triste e reativo da primeira sessão acolher sua própria história e suas emoções. Por mais doloridas e difíceis que fossem, Banner se permitiu olhar para as cenas que traziam sofrimento e angústia por meio do uso da metáfora do Hulk e do portal secreto.

O Banner da primeira sessão trazia narrativas nas quais se menosprezava e acreditava não ter valor, chegando a se considerar um menino que todos abandonavam. O Banner da última sessão pôde se conectar, a partir da exteriorização do Hulk e da entrada no portal, com novos enredos, os quais ele coconstruiu com sua terapeuta. Gergen e Gergen (2010) provocam um questionamento importante: "Será que tudo que construímos como 'problema' não poderia ser reconstruído como 'oportunidade'?” (p. 22) Ficamos pensando nessa palavra e como ela pode ser essencial no processo. Afinal, Banner disse, ao sair: "obrigado por ter me dado uma chance". Será que não poderíamos dizer: uma oportunidade?

O Hulk que há dentro de Banner, num primeiro momento, é visto como violento, agressivo, desrespeitoso, mal-agradecido. Banner levava às sessões o lugar desagradável do Hulk e o quanto era o responsável por não ser amado e desejado nas 
relações. Concluímos que a postura de "não saber", durante o processo terapêutico, em que o diálogo se transforma numa conexão sem invasão, com respeito e afeto, foi primordial para que o Hulk fosse se transformando em super-herói e com uma potência enorme para auxiliar Banner a falar da sua história e das suas emoções. Ele pôde ter raiva, tristeza, e estava tudo bem desgostar de algo, discordar de alguém.

A metáfora, como um recurso da linguagem, traduziu para Banner as emoções que ele não entendia ou sobre as quais não queria falar, ao mesmo tempo em que mostrou que elas faziam parte dele. Esse recurso teve como objetivo acompanhar a terapeuta e o cliente no processo de ressignificação de suas histórias, permitindo que o cliente acessasse novas narrativas, novas emoções, novos jeitos de falar sobre "problemas". Dessa forma, permite-se que os "problemas" se transformem em oportunidades e em (re)começos.

Assim, a viagem ao mundo de fantasia e imaginação chegou ao fim neste cenário terapêutico. Trabalhar com Banner e, por extensão, com toda a sua família, nos permitiu adentrar as histórias de super-heróis, portais, viagens no tempo, os faz de conta, disputas entre inimigos, enfrentamento de pessoas do passado, do presente e do futuro. A criatividade e a flexibilidade fizeram parte da nossa relação com Banner. Elas nos ajudaram na abertura e disposição necessárias para coconstruírmos novas três narrativas, a de Banner, a da terapeuta e a da supervisora. Todos saíram com novos significados para suas histórias.

Como todo final do David Banner, atualmente, o Hulk ainda anda por aí...

\section{REFERÊNCIAS}

Anderson, H. (2009). Conversação, linguagem e possibilidades: um enfoque pósmoderno da terapia. São Paulo: Rocca

Anderson, H. (2017a). A postura filosófica: o coração e a alma da prática colaborativa. In M. Grandesso (Org.), Práticas colaborativas e dialógicas em distintos contextos e populações: um diálogo entre teoria e práticas (pp. 21-34). Curitiba, PR: CRV.

Anderson, H. (2017b). Diálogo: pessoas criando significados umas com as outras e encontrando maneiras de continuar. In M. Grandesso (Org.), Práticas colaborativas e dialógicas em distintos contextos e populações: um diálogo entre teoria e práticas (pp. 93-103). Curitiba, PR: CRV.

Basford, J. (2014). Jardim Secreto: livro de colorir e caça ao tesouro antiestresse. Rio de Janeiro: Sextante.

Caminha, R. M. \& Caminha, M. G. (2008). Baralhodas Emoções: acessando a criança no trabalho clínico. Porto Alegre: Sinopsys.

Faleirros, V. P.s \& Moraes, P. J. F. S. (2015). Desafios e possibilidades na adoção. Serviço Social e Saúde, 13(1), 29-46. https://doi.org/10.20396/sss.v13i1.8634913

Gergen, K. J. \& Gergen, M. (2010). Construcionismo Social: um convite ao diálogo. Rio de Janeiro: Instituto Noos.

Grandesso, M. (2012). Terapia de família centrada na criança: a criança como parceira conversacional. In H. M. Cruz (Org.), Me aprende? Construindo lugares seguros para crianças e seus cuidadores (pp. 41-70). São Paulo: Roca.

Grandesso, M. (2017). Terapia como reconstrução de significados: um enfoque pósmoderno para a terapia. In Práticas colaborativas e dialógicas em distintos contextos e populações: um diálogo entre teoria e práticas (pp. 167-181). Curitiba: CRV.

Maesima, G. M., Barreto, M., \& Beiras, A. (2019). O conceito de ressonâncias no processo de formação do terapeuta: descobrindo potencialidades e limitações na prática terapêutica. Nova Perspectiva Sistêmica, 28(64), 105-118. Recuperado de https://www.revistanps.com.br/nps/article/view/501 
Müller, A. (2017). Ritmos da vida: ajudando crianças na superação da separação. Nova Perspectiva Sistêmica, 22(45), 35-47. Recuperado de https://www.revistanps. com.br/nps/article/view/229

Grandesso, M. \& Paschoal, V. N. (2016). O uso de metáforas em terapia narrativa: facilitando a construção de novos significados. Nova Perspectiva Sistêmica, 23(48), 24-43. Recuperado de https://www.revistanps.com.br/nps/article/view/48

Rasera, E. F. (2018). Grupo como construçao social: aproximações entre construcionismo social e terapia de grupo. São Paulo: Instituto Noos.

Schettini, L. (2009). Pedagogia da adoção: criando e educando filhos adotivos. Petrópolis, RJ: Vozes.

Schettini, S. S. M., Amazonas, M. C. L. A., \& Dias, C. M. S. B. (2006). Famílias adotivas: identidade e diferença. Psicologia em Estudo, 11(2), 285-293. Recuperado de http://www.scielo.br/pdf/pe/v11n2/v11n2a06.pdf

Vasconcellos, M. J. (2002). Pensamento sistêmico: o novo paradigma da ciência. Campinas, SP: Papirus.

White, M. (2012). Mapas da prática narrativa. Porto Alegre: Pacartes.

\section{MARIANA PERES TRAJANO}

Psicóloga especialista em Terapia Cognitivo-Comportamental e Terapia Sistêmica. Mestre em Saúde Mental e Atenção Psicossocial pela Universidade Federal de Santa Catarina (2017). Atua como psicóloga clínica.

https://orcid.org/0000-0001-9107-9575

E-mail: mariana.p.trajano@gmail.com

\section{MONICA DUARTE DA SILVA GONÇALVES}

Mestre em Psicologia pela Universidade Federal de Santa Catarina (2002). Didatasupervisora em Psicodrama, especialista pela SOCIUS em grupos e especialista em Terapia Relacional Sistêmica pelo Instituto Familiare. Deu aulas na UFSC, FURB e CESUSC. Atua como psicóloga clínica desde 1997 e como supervisora clínica desde 2002. Desde 2008 vem se envolvendo com o movimento artístico em Florianópolis. https://orcid.org/0000-0002-7029-5807

E-mail: monica.moniarte@gmail.com 